\title{
Effects of drying pretreatments on the analysis of the mercury fraction in sediments
}

\author{
Qunqun Liu • Jiangmin Song • Tao Ma • Ming Jiang • \\ Guangxiang Ma $\cdot$ Yanqing Sheng
}

Received: 19 July 2019 / Accepted: 27 August 2019 / Published online: 4 September 2019

(C) Springer Nature Switzerland AG 2019

\begin{abstract}
The geochemical fractions of heavy metals in sediments are crucial indexes for their mobility and bioavailability evaluations. However, different drying processes of sediment pretreatment could change metal geochemical fractions, especially for $\mathrm{Hg}$, which is potentially volatile. In this study, the influence of pretreatment methods including oven-drying, air-drying, freezedrying, and fresh sediments on the analysis of $\mathrm{Hg}$ fractions in sediments was investigated. Results showed that remarkable differences of $\mathrm{Hg}$ concentration were observed between fresh sediments and dried pretreatment sediments $(P<0.05)$. Briefly, the concentrations of the water-soluble and human stomach acid-soluble fractions in oven-dried and air-dried sediments generally showed significant increasing trends compared with those in the fresh sediments, while the organo-chelated fraction exhibited significant decreasing trends. The cause of this phenomenon was primarily the oxidation of organic matter, aging process, and the diffusion of $\mathrm{Hg}$ into micropores. The significant loss was also observed at elemental $\mathrm{Hg}$ fraction due to its volatilization effect.
\end{abstract}

Q. Liu · J. Song $\cdot$ T. Ma $\cdot$ M. Jiang $\cdot$ Y. Sheng $(\bowtie)$

Research Center for Coastal Environment Engineering

Technology of Shandong Province, Yantai Institute of Coastal

Zone Research, Chinese Academy of Sciences, Yantai, China

e-mail: yqsheng@yic.ac.cn

Q. Liu · J. Song $\cdot$ M. Jiang

University of Chinese Academy of Sciences, Beijing, China

T. Ma $\cdot$ G. Ma

Shandong Academy of Environmental Science Co., Ltd.,

Jinan 250100, People's Republic of China
The freeze-drying posed minor influence on changes of $\mathrm{Hg}$ fraction analysis compared with oven-drying and air-drying. Moreover, the total $\mathrm{Hg}$ concentrations in pretreated sediments showed a decline of varying degrees compared with those in fresh sediments ascribing to the volatilization of elemental Hg. Finally, Pearson correlation analysis further confirmed that freeze-drying could minimize the errors of the $\mathrm{Hg}$ fraction analysis in sediments.

Keywords Sediments · Mercury · Pretreatment · Drying methods $\cdot$ Sequential extraction procedures $\cdot$ Metal fraction

\section{Introduction}

Mercury ( $\mathrm{Hg}$ ) has been classified as an environmental priority pollutant by many international institutions because of its biological toxicity and hard degradation in the environment (Jiang et al. 2006). With the vigorous development of industry and agriculture, more $\mathrm{Hg}$ was directly or indirectly discharged into reservoirs, rivers, and lakes by surface runoff (Azad et al. 2019); moreover, atmospheric deposition has also been identified as an important source of $\mathrm{Hg}$ in aquatic environments (Kang et al. 2016). Mercury in overlying water is easily scavenged by suspended particulate matter and subsequently deposited to surface sediments (Liu et al. 2018). Conversely, accumulated $\mathrm{Hg}$ in sediments can be rereleased after changes in the sediment environment (Machado et al. 2016). Therefore, sediments are a major 
sink and source for $\mathrm{Hg}$ in aquatic environments (Pan and Wang 2012). The toxicity of metals, including $\mathrm{Hg}$, to living beings in sediments largely depends on their mobility and bioavailability; however, the total metal concentration only provides very limited information (Nemati et al. 2011; Liu et al. 2018). Therefore, much sequential extraction procedures have been proposed to detect the mobility and bioavailability of heavy metals in sediments (Huang et al. 2015; Liu et al. 2018).

The most ideal way to analyze the heavy metal fraction in sediments is to directly handle fresh sediments. However, this is not always possible or realistic in field work due to the complexity of the analytical procedures. In addition, the excessive water moisture can increase many inconveniences for subsequent treatment, and the inhomogeneity of natural sediments also can cause measurement errors. For these reasons, sediments are often performed with drying pretreatments prior to analysis. There are three common drying methods for sediment pretreatment before heavy metal fraction analysis: air-drying (AD), oven-drying (OD), and freeze-drying (FD). Generally, AD takes the longest time ( $\sim 14$ days); FD is a timesaver ( $\sim 3$ days), but the operation is complex, and the equipment is expensive; finally, OD is relatively convenient, but its negative effects are significant, especially for volatile heavy metals. Furthermore, AD and OD are accompanied by an oxidation process, which can destroy the original physicochemical properties of sediments and affect the heavy metal fractions in sediments (Long et al. 2009; Huang et al. 2015). Therefore, an appropriate drying method is necessary to ensure accurate analysis for geochemical fractions of target heavy metals. Previous studies have reported that drying processes can lead to heavy metal fraction transformation because of changes in the redox conditions and temperatures, especially for anoxic sediments (Baeyens et al. 2003; Claff et al. 2010). Consequently, inappropriate drying pretreatment may distort the accuracy of results. However, recent studies have mainly focused on non-volatile heavy metals (e.g., $\mathrm{Cu}, \mathrm{Pb}, \mathrm{Zn}$, and $\mathrm{Cd}$ ) (Zhang et al. 2001; Claff et al. 2010; Huang et al. 2015); the effects of sample pretreatment on the $\mathrm{Hg}$ fraction are unknown. Therefore, it is important and necessary to evaluate the effects of drying pretreatment on the determination of $\mathrm{Hg}$ fractions in sediments.

The objectives of this study are (1) to investigate the effects of $\mathrm{AD}, \mathrm{OD}$, and $\mathrm{FD}$ on the analyses of $\mathrm{Hg}$ fraction in sediments followed by a multistep sequential extraction procedure and (2) to select an appropriate drying method for sedimental $\mathrm{Hg}$ fraction determination compared with fresh sediment analysis. The results provided a technical reference for further $\mathrm{Hg}$ fraction analysis, ensuring the accuracy of ecological risk assessments of $\mathrm{Hg}$ in sediments.

\section{Materials and methods}

Sample collection

Surface sediment samples $(0-10 \mathrm{~cm})$ were collected from the estuary of Jiahe River (JR) and the Guangdong River (GR) in the Shandong Peninsula of China in October 2018. The JR has been mainly used for agricultural irrigation and drinking water. The GR is an urban river and primarily receives domestic sewage and industrial effluents along the river. Four surface sediment samples (two samples from each river) were collected using a Van-Veen grab sampler. Samples were placed into polyethylene bags, stored in a plastic icecold container, and then transported to the laboratory for further analysis.

\section{Sample pretreatment and characterization}

Large stones, plant roots, and other impurities were first removed from the sediments, which were slightly stirred to homogenize the samples. To avoid the risk of oxidation, all steps were carried out in an operating box filled with nitrogen gas. Before determination, each sediment sample was divided into four parts. The pretreatments were as follows: (1) the fresh sample at $4{ }^{\circ} \mathrm{C}$ was analyzed directly (FS); (2) the sample was oven-dried at $40{ }^{\circ} \mathrm{C}$ for $72 \mathrm{~h}$ for further analyzes (OD); (3) the airdried sample was prepared at $25{ }^{\circ} \mathrm{C}$ for 2 weeks before detection (AD); and (4) the sample for determination was frozen at $-20^{\circ} \mathrm{C}$ and was vacuum freeze-dried for $72 \mathrm{~h}(\mathrm{FD})$.

The percentage of moisture (MO) of the sediments was calculated by heating at $105^{\circ} \mathrm{C}$ to achieve a constant weight. The grain sizes were determined using a Malvern Particle Size Analyzer (MS 2000, Malvern, UK). The $\mathrm{pH}$ and electrical conductivity (EC) were measured by a 1:5 sediments suspension. The total organic carbon (TOC) was analyzed by a TOC analyzer (Vario Micro cube, German). Acid volatile sulfide (AVS) in sediments was measured using a modified 
method of the cold diffusion procedure (Sheng et al. 2015). Briefly, the AVS was extracted by $9 \mathrm{M} \mathrm{HCl}$ and $\mathrm{CuCl}_{2}$ solutions in order; the end product $\mathrm{CuS}$ was used for calculating AVS contents in sediments.

Sequential extraction procedure and metal analysis

After the four pretreatments of drying processes, geochemical fractions of $\mathrm{Hg}$ in samples were analyzed using sequential selective extraction as described by Bloom et al. (2003), respectively. This method is considered as the most suitable method for analyzing the $\mathrm{Hg}$ fraction in sediments due to its high selectivity and simple operation (Zhong and Wang 2008; FernándezMartínez and Rucandio 2013; Budianta et al. 2019). The $\mathrm{Hg}$ fractions in sediments were classified into five behavioral classes: (a) water-soluble (F1), (b) human stomach acid-soluble (F2), (c) organo-chelated (F3), (d) elemental $\mathrm{Hg}$ (F4), and (e) mercuric sulfide (F5) (Bloom et al. 2003). The samples pretreated by OD, $\mathrm{FD}$, and $\mathrm{AD}$ were sieved by $0.150 \mathrm{~mm}$ mesh, and $1.0 \mathrm{~g}$ samples were weighed in $100-\mathrm{mL}$ centrifuge tubes, respectively. For the FS samples, 1.5-2.5 g (equiv. dw) samples were weighed in $100-\mathrm{mL}$ centrifuge tubes in the nitrogen operating box. The detailed sequential extraction procedure is shown in Table 1. Then, each extraction solution was obtained through centrifugation (4000 rpm, $25 \mathrm{~min}$ ), and corresponding $\mathrm{Hg}$ concentrations in each extraction solution were measured by atomic fluorescence spectrometry (AFS, 930, Beijing Jitian Instruments Co. Ltd, China). For the total $\mathrm{Hg}$ determination, the different pretreatment sediment samples were digested by $\mathrm{HNO}_{3}-\mathrm{HF}-\mathrm{HClO}_{4}$ prior to analysis, and total $\mathrm{Hg}$ concentrations in digestion were also tested by AFS.

Change rates of different pretreatments compared with FS

To evaluate the effects of drying pretreatments on $\mathrm{Hg}$ fraction analysis in sediments, the rate of different pretreatments compared with the FS was calculated as follows:

$\eta=\frac{C_{\mathrm{FS}}-C_{D}}{C_{\mathrm{FS}}} \times 100 \%$

where $\eta$ is the change rate (\%), and $C_{\mathrm{FS}}$ and $C_{D}$ are the concentrations of $\mathrm{Hg}$ obtained from each of fresh
Table 1 Schemes of sequential selective extractions for $\mathrm{Hg}$ in sediments

\begin{tabular}{|c|c|c|}
\hline Step & $\begin{array}{l}\text { Target } \\
\text { fractions }\end{array}$ & Reagents and treatments \\
\hline 1 & $\mathrm{~F} 1$ & $\begin{array}{l}\text { Deionized water (purged with high-purity } \\
\text { argon), room temperature, agitation for } 18 \mathrm{~h} \\
(30 \mathrm{rpm})\end{array}$ \\
\hline 2 & $\mathrm{~F} 2$ & $\begin{array}{l}0.01 \mathrm{M} \mathrm{HCl}+0.1 \mathrm{M} \mathrm{CH}_{3} \mathrm{COOH}, \text { room } \\
\text { temperature, agitation for } 18 \mathrm{~h}(30 \mathrm{rpm})\end{array}$ \\
\hline 3 & F3 & $\begin{array}{l}1 \mathrm{M} \mathrm{KOH} \text {, room temperature, agitation for } \\
18 \mathrm{~h}(30 \mathrm{rpm})\end{array}$ \\
\hline 4 & F4 & $\begin{array}{l}12 \mathrm{M} \mathrm{HNO}_{3} \text {, room temperature, agitation for } \\
18 \mathrm{~h}(30 \mathrm{rpm})\end{array}$ \\
\hline 5 & F5 & $\mathrm{HF}+\mathrm{HNO}_{3}+\mathrm{HF}$, microware digestion \\
\hline
\end{tabular}

sediments and the dried sediments in a particular fraction, respectively.

\section{Quality control}

All reagents were guaranteed of analytical grade. Each sediment samples was treated in triplicate, and the relative standard deviations were less than $10 \%$. Stream sediment reference material (GBW 07311, GSD-11, Institute of Geophysical and Geochemical Exploration, Chinese Academy of Geological Sciences) was used for the quality control of total $\mathrm{Hg}$ detection, and the recovery was $86.21 \%$. The ratios of the sum of five fractions to the total content of $\mathrm{Hg}$ in sediments were 83.64$108.84 \%$ for FS, 82.32-95.38\% for OD, 83.56$91.59 \%$ for $\mathrm{AD}$, and $89.85-99.12 \%$ for $\mathrm{FD}$, implying the reliability and creditability of the fraction analysis.

\section{Statistical analysis}

SPSS 19.0 and MS-Excel® 2010 were used for the statistical analysis of measured data. The data were tested for normality with the method of KolmogorovSmirnov (K-S) before conducted to parametric test. If data presented no normality, they were performed to logarithmic transformation. One-way ANOVA with Tukey's and Games-Howell tests at a significance level of 0.05 were employed to test significant differences between the different fraction contents in different pretreatments. Pearson's correlation coefficient $(r)$ was performed to identify their relationships and further select a more suitable drying method. 


\section{Results and discussion}

\section{Characteristics of sediments}

Characteristics of the sediments are listed in Table 2. The $\mathrm{pH}$ values were close to each other and exhibited weak alkalinity. The EC presented low values $(<1 \mathrm{~ms} /$ $\mathrm{cm})$. The $\mathrm{MO}$ of the samples exceeded $50 \%$ except for JR1 $(<43.66 \pm 5.01)$. Generally, particle size and TOC are important factors controlling the spatial distribution of heavy metals (Zhu et al. 2016). In the present study, the TOC $(\%)$ in GR $(5.10 \pm 0.64$ for GR1 and $2.51 \pm$ 0.17 for GR2) was higher than that in JR $(1.10 \pm 0.08$ and $0.90 \pm 0.13)$, indicating that organic matter was seriously enriched in GR. The particle sizes were dominated by sand and silt (> 94\%) in all sampling sites except for GR1 (clay $>21 \%$ ). As the reported of Ma et al. (2019), the vast majority of mobile heavy metal fractions remained as fine particles compared with the large particles in sediments. The highest AVS value was in GR1, which possessed a high TOC (5\%), and the lowest AVS value was observed at site JR2 with a low TOC (1\%). Previous studies have also confirmed that AVS in sediments can be influenced by organic matters, which always accompany with abundant AVS (Habicht and Canfield 1997). Moreover, high AVS value was accumulated in sediment, especially for GR1, indicating that sediment was under anoxic conditions (Morse and Rickard 2004; Bottrell et al. 2009).

Comparison of different pretreatment methods

\section{F1 fraction}

The F1 fraction in sediments extracted by sequential selective extraction was mainly made up of inorganic mercury $\mathrm{Hg}(\mathrm{II})$, such as $\mathrm{HgCl}_{2}, \mathrm{HgSO}_{4}$, and $\mathrm{HgO}$ (Bloom et al. 2003), and this fraction is readily released into environments to damage aquatic organisms. Therefore, the change of $\mathrm{Hg}$ fractions is vital for the ecological risk assessment and remediation of sediments. As shown in Fig. 1, F1 fraction contents in the OD and AD samples exhibited significant elevation $(P<0.05)$ compared with those in the FS. The results indicated that F1 fraction was significantly affected by the drying pretreatment due to the oxidation of AVS and the decomposition or oxidation of organic matter. Generally, divalent metal ions $\left(\mathrm{M}^{2+}\right.$, e.g., $\mathrm{Cd}^{2+}, \mathrm{Cu}^{2+}, \mathrm{Zn}^{2+}$, and $\mathrm{Hg}^{2+}$ ) can combine with AVS to form metal sulfide
(MS) precipitates under anoxic conditions in sediments (Pignotti et al. 2018). However, the heavy metals $\left(\mathrm{M}^{2+}\right)$ can be released again into environment when the MS was oxidized (Di Toro et al. 1992; Huerta-Diaz et al. 1998). This process briefly exhibited two reactions (Meysman and Middelburg 2005):

$M^{2+}+F e S(S) \leftrightarrow F e^{2+}+M S(S)$

$\mathrm{MS}(\mathrm{S})+2 \mathrm{O}_{2} \rightarrow \mathrm{SO}_{4}{ }^{2-}+\mathrm{M}^{2+}$

For the FD sample, although the significant elevation $(P<0.05)$ was observed, the change rates were more minor compared with $\mathrm{OD}$ and AD. This was mainly because FD can partly avoid oxidation during the drying process. Moreover, previous studies have reported that drying also promotes the decomposition of organic matter and can lead to more residual forms of organic matter turning into more available fractions, which can be easily extracted in determination (Klitzke and Lang 2007; Huang et al. 2015). The change rates of the OD, $\mathrm{AD}$, and FD pretreatments for F1 compared with the FS are listed in Table 3. For the same sample, different drying pretreatments showed significantly different change rates. For example, change rates of $\mathrm{OD}, \mathrm{AD}$, and FD were $256.05 \%, 161.98 \%$, and $101.98 \%$ in GR2, respectively. This was primarily due to the different oxidation rates of their pretreatments, and longer drying time and higher temperature of drying process can promote the decomposition and oxidation of organic matter (Huang et al. 2015). The change rates of AD in GR2 were lower than those of OD; this was because the mobile fraction metals decreased along the increased AD time in the aging process (Quazi et al. 2011). However, the contrary result was observed at OD and AD in JR2. Previous studies have confirmed that heavy metals associated with the weak bound fractions decrease along with the temperature increases as heavy metal ions diffuse into the clay mineral micropores of (Barrow 1992; Ma et al. 2006; Huang et al. 2015). Hence, the diffusion of $\mathrm{Hg}(\mathrm{II})$ from the inner-sphere surface into the micropores of clay minerals was strengthened by high temperature during oven-drying. In addition, the change rates of same pretreatment for different sediments also showed some differences, and the great differences in sediment characteristics (Table 2) were responsible for their change rates in same pretreatment. For instance, 
Table 2 Characteristics of sediment samples in the study area

\begin{tabular}{lllllllll}
\hline Sites & pH & EC (ms/cm) & MO $(\%)$ & TOC $(\%)$ & Sand (\%) & Silt (\%) & Clay (\%) & AVS (mg/kg) \\
\hline GR1 & $7.79 \pm 0.10$ & $0.68 \pm 0.04$ & $73.19 \pm 3.42$ & $5.10 \pm 0.64$ & $30.66 \pm 4.10$ & $47.38 \pm 3.12$ & $21.96 \pm 0.13$ & $2136.32 \pm 144.96$ \\
GR2 & $7.71 \pm 0.12$ & $0.50 \pm 0.07$ & $61.80 \pm 4.20$ & $2.51 \pm 0.17$ & $56.76 \pm 4.39$ & $40.87 \pm 3.78$ & $2.37 \pm 0.09$ & $1175.68 \pm 24.00$ \\
JR1 & $7.93 \pm 0.23$ & $0.48 \pm 0.09$ & $43.66 \pm 5.01$ & $1.10 \pm 0.08$ & $61.81 \pm 4.78$ & $35.70 \pm 4.10$ & $2.49 \pm 0.25$ & $389.44 \pm 3.20$ \\
JR2 & $7.97 \pm 0.21$ & $0.78 \pm 0.04$ & $68.32 \pm 7.89$ & $0.90 \pm 0.13$ & $40.11 \pm 3.17$ & $54.15 \pm 4.01$ & $5.74 \pm 0.98$ & $56.64 \pm 0.64$ \\
\hline
\end{tabular}

the TOC in JR1 was higher than that in JR2. More organic matters were enriched in the sediments, and correspondingly more heavy metals associated with the organic matter were released once they were decomposed or oxidized. Overall, F1 concentrations pretreated by OD and AD were elevated compared with the FS in anoxic sediments because the $\mathrm{Hg}$ stored in stable fractions can be mobilized through the oxidation of AVS and the decomposition of organic matter.

\section{F2 fraction}

The F2 fraction is also one of the major proportions of bioavailable $\mathrm{Hg}$ in sediments and mainly contained $\mathrm{HgO}, \mathrm{HgSO}_{4}$, and $\mathrm{HgCl}_{2}$, which is similar to the $\mathrm{F} 1$ fraction (Bloom et al. 2003). Usually, the sum of the F1 and F2 extractions can be almost dissolved by the bioavailability measures of operationally defined (e.g., in vitro human stomach simulation) (Bloom et al. 2003). The drying influences on the F2 fraction of $\mathrm{Hg}$ are illustrated in Fig. 2. The F2 fraction in the AD and OD samples showed significant enhancement $(P<0.05)$ compared with that in FS. Similar to the F1 fraction, the elevation of the F2 fraction was mainly due to the oxidation of AVS and the decomposition of organic matter. Notably, although the F2 fraction FD samples also presented a significant increase, the change rate was lower than that in $\mathrm{AD}$ and $\mathrm{OD}$ for the slighter oxidation effect of FD pretreatment. The F2 of GR1 and GR2 treated by OD presented some drops compared with the FS, while the F2 fraction in JR1 and JR2 showed increases (Table 3). As mentioned above, the diffusion of $\mathrm{Hg}$ (II) from the inner-sphere surface into the micropores of clay minerals was enhanced during OD at higher temperatures, which was responsible for the decrease of F2 fraction in GR1 and GR2.

Although the major F1 and F2 components were similar, the F2 contents were much higher than the F1 concentrations in all samples (Figs. 1 and 2). This was mainly due to differences in the extraction procedures; the $\mathrm{pH}$ of the $\mathrm{F} 2$ fraction extractant $\left(0.1 \mathrm{M} \mathrm{CH}_{3} \mathrm{COOH}+\right.$ $0.01 \mathrm{M} \mathrm{HCl}$ ) was much lower than that of the $\mathrm{F} 1$ extractant (deionized water). It is known that lower $\mathrm{pH}$ can promote the release of heavy metals from sediments
Fig. 1 Drying influence on the $\mathrm{F} 1$ fraction of $\mathrm{Hg}$ in the different sediment samples
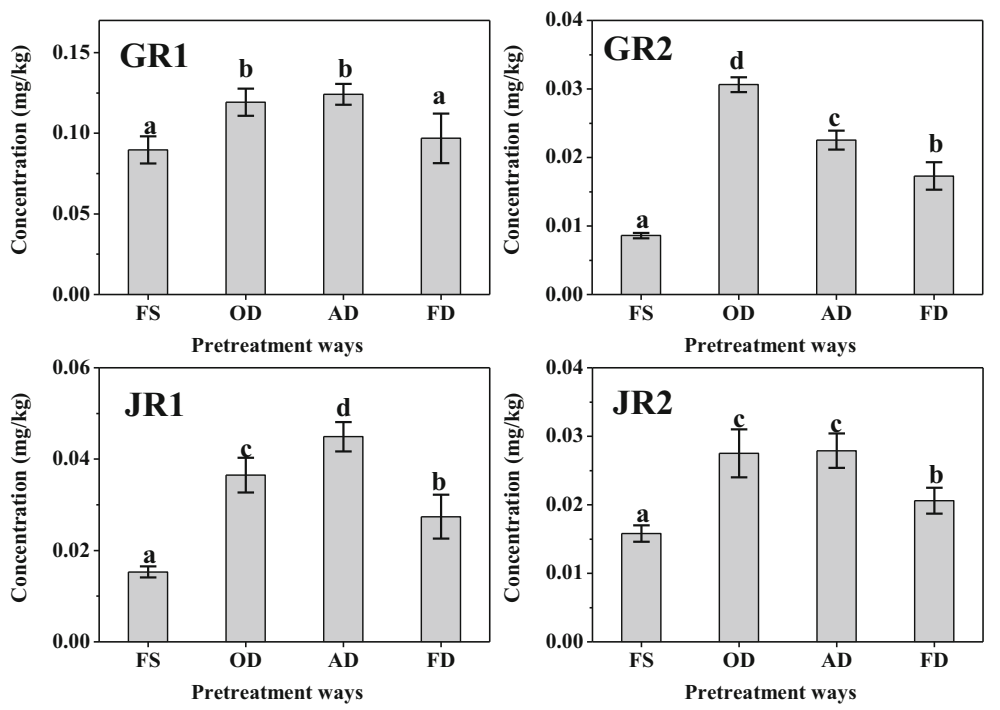
Table 3 The change rates of each pretreatment on the $\mathrm{Hg}$ fraction compared with FS

\begin{tabular}{lllll}
\hline Pretreatment & GR1 $(\%)$ & GR2 $(\%)$ & JR1 $(\%)$ & JR2 $(\%)$ \\
\hline F1 & & & & \\
OD & 32.93 & 256.05 & 138.56 & 74.05 \\
AD & 38.45 & 161.98 & 193.46 & 76.58 \\
FD & 8.03 & 101.16 & 79.09 & 30.38 \\
F2 & & & & \\
OD & -17.99 & -35.14 & 100.01 & 44.44 \\
AD & 30.16 & 118.92 & 78.79 & 36.11 \\
FD & 6.35 & 52.42 & 42.42 & 16.67 \\
F3 & & & & \\
OD & -35.12 & -61.97 & -33.23 & -14.82 \\
AD & -29.89 & -31.12 & -30.81 & -14.27 \\
FD & -19.06 & -24.20 & -15.21 & -13.98 \\
F4 & & & & \\
OD & -46.23 & -51.77 & -31.97 & -38.86 \\
AD & -33.09 & -35.92 & -26.38 & -24.98 \\
FD & -15.45 & -18.01 & -13.34 & -24.60 \\
F5 & & & & \\
OD & -4.26 & 1.25 & -5.21 & -1.41 \\
AD & -2.03 & -6.16 & 16.56 & -5.19 \\
FD & -0.84 & -3.87 & -5.30 & 6.08 \\
\hline
\end{tabular}

(Cabon et al. 2010). Similar to F1, the change rates of F2 greatly varied with different sampling sites and different pretreatment methods. The reason for these phenomena was the differences in sediment properties and oxidation effect of the different pretreatments.

\section{F3 fraction}

The F3 fraction was mainly associated with organic matter, and $\mathrm{MeHg}$ and $\mathrm{Hg}$-humic were primarily found in this fraction (Bloom et al. 2003). The pretreatment effect of OD and AD on F3 fraction showed significant decrease $(P<0.05$; Fig. 3$)$. In general, organo-chelated heavy metals are chelated with various forms of organic matter that originates from animal and plant residues, humus and proteins, and the inclusion of mineral particles (Haitzer et al. 2003; Liu et al. 2018). When sample was dried, organic matter could be degraded and the bound metal $(\mathrm{Hg})$ can be released. Then, this F3 fraction of $\mathrm{Hg}$ was extracted. Especially for AD process, the photochemical demethylation of $\mathrm{MeHg}$, in which the $\mathrm{Hg}$ (II) can be photodegraded into elemental $\mathrm{Hg}$, may be an important reason for the decreased F3 fraction ( $\mathrm{Li}$ et al. 2010; Black et al. 2012).

In addition, the variation of volatile fatty acids (VFA) in sediments cannot be ignored because VFA concentrations in samples greatly decrease after drying (Long et al. 2009). The loss of VFA may cause the Hg that is combined with the VFA to be extracted in the F1 and F2 fractions. Thus, the F3 fraction concentrations showed an increase, while the F1 and F2 concentrations were accordingly higher. As for FD, significant decrease of F3 fraction was only observed at GR2 due to its weak oxidation effect. Notably, the change rates in the same sediments showed significant variations in the pretreatments of FD, AD, and OD compared with the FS $(P<$ $0.05)$, suggesting that the effects on the F3 fraction by the three pretreatments should be also serious. Furthermore, the change rates treated by the same pretreatment on the different samples also showed large differences. For example, the change rates of OD in GR1, GR2, JR1, and JR2 were $-35.12 \%,-61.97,-33.23 \%$, and $14.82 \%$, respectively (Table 3 ).

\section{F4 fraction}

The F4 fraction extracted by $12 \mathrm{M} \mathrm{HNO}_{3}$ solution consists of $\operatorname{Hg}(0)$ (elemental $\mathrm{Hg}$ ) (Bloom et al. 2003). The formation of $\operatorname{Hg}(0)$ is mainly due to the reduction of $\mathrm{Hg}$ (II) and the degradation of $\mathrm{MeHg}$ in natural environment (Leopold et al. 2010). Although $\mathrm{Hg}(0)$ is predominantly found in the atmosphere, sediments also accumulate an amount of $\operatorname{Hg}(0)$ (Hellmann et al. 2019). In sediments, $\mathrm{MeHg}$ can be degraded and transformed into $\mathrm{Hg}(0)$ by bacteria, and $\mathrm{Hg}(\mathrm{II})$ is reduced to $\mathrm{Hg}(0)$ (Leopold et al. 2010). Finally, a part of $\operatorname{Hg}(0)$ is released into the atmosphere through the water column. As shown in Fig. 4, the F4 concentrations exhibited a significant decrease $(P<0.05)$ in all drying pretreatments. Elemental $\mathrm{Hg}$ is very likely to volatilize as its considerable vapor pressure at room temperature (Hellmann et al. 2019). Consequently, a drying process could cause the elemental $\mathrm{Hg}$ in sediments to evaporate into the atmosphere and result in the loss of elemental $\mathrm{Hg}$. For all the drying methods, the decreased extent in OD was higher than that in other pretreatments, while OD was the lowest (Table 3). Usually, elemental $\mathrm{Hg}$ is volatilized at room temperature, and the high temperature $\left(60^{\circ} \mathrm{C}\right)$ could promote the volatilization of elemental $\mathrm{Hg}$ in the pretreatment of OD. The FD can minimize volatilization of elemental $\mathrm{Hg}$. 
Fig. 2 Drying influence on the $\mathrm{F} 2$ fraction of $\mathrm{Hg}$ in the different sediment samples
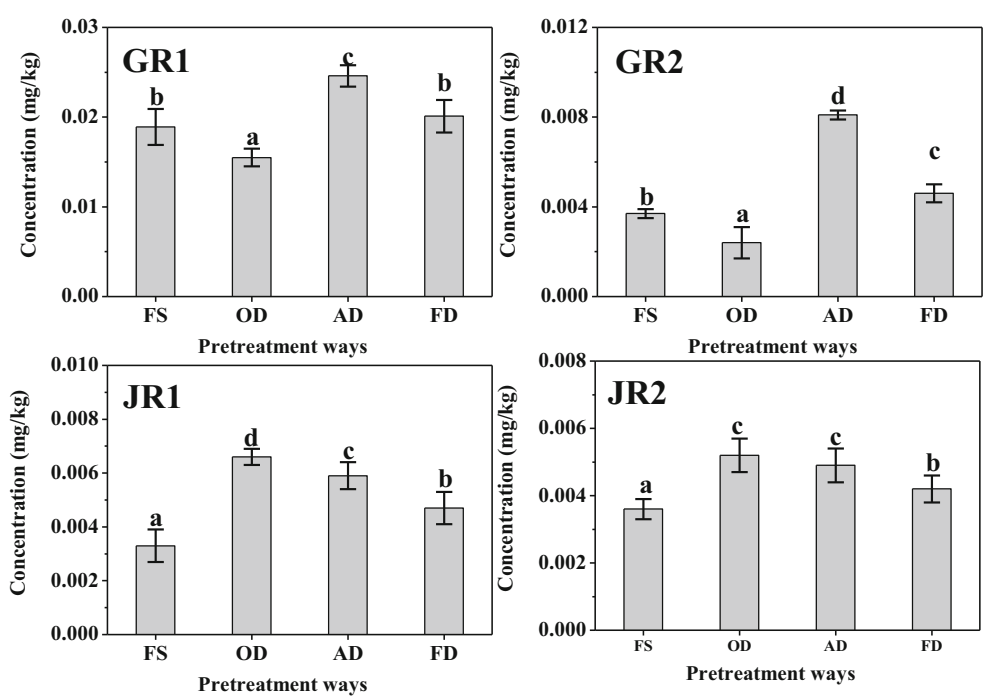

\section{F5 fraction}

As shown in Fig. 5, the F5 fraction exhibited no obvious distinction among all dying pretreatments. The F5 fraction of $\mathrm{Hg}$ was mainly composed by $\mathrm{HgS}$ and is bound with the strongest association to the crystalline structures of minerals with the lowest water solubility and the most stable physicochemical properties (Bloom et al. 2003). In general, F5 concentrations in the samples of dried by pretreatment were lower than those in the FS (Table 3). The minor changes in the different drying methods could be related to the increase or decrease of former fractions. As reported by Bloom et al. (2003), the compound $\mathrm{HgS}$ can be slightly oxidized to soluble forms during extraction; and the $\mathrm{HgS}$ can also be oxidized during the drying process once exposed. In addition, original surface structure could be destroyed during the grinding process to induce the release of the $\mathrm{Hg}$ from the crystalline structures of the minerals in the early extraction steps (Claff et al. 2010).

Notably, the F5 fraction contents exhibited an increase in OD in GR2, AD in JR1, and FD in JR2. This increase may be related to the crystallization of hydrous iron oxides because the crystallization of hydrous iron oxides can be generally promoted during the drying process (Thompson et al.
Fig. 3 Drying influence on the $\mathrm{F} 3$ fraction of $\mathrm{Hg}$ in the different samples
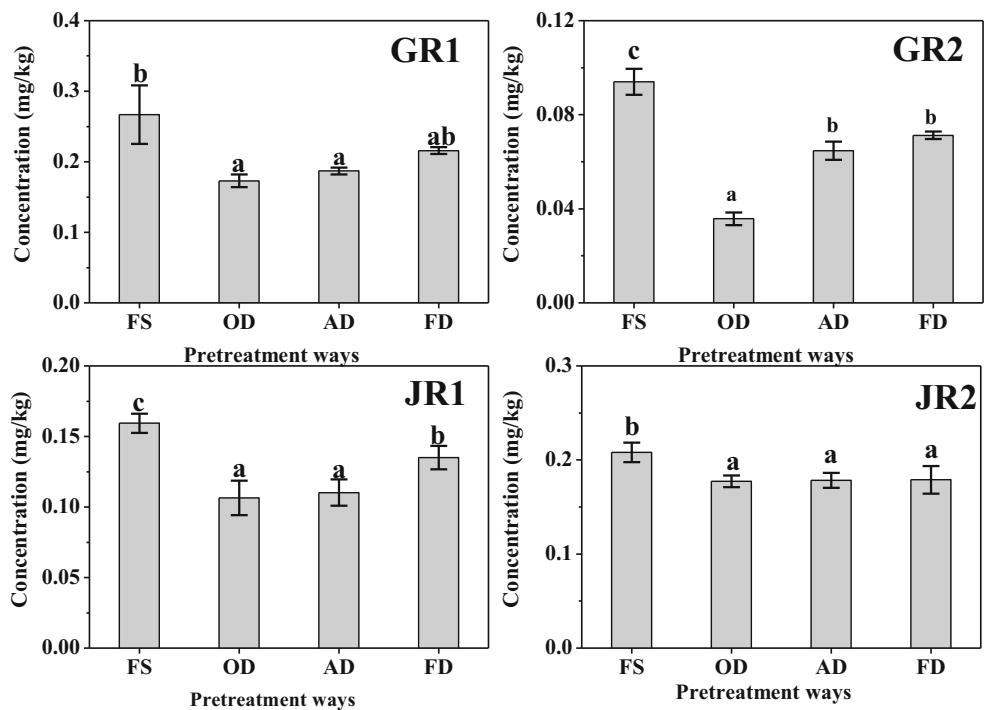
Fig. 4 Drying influence on the F4 fraction in the different sediment samples
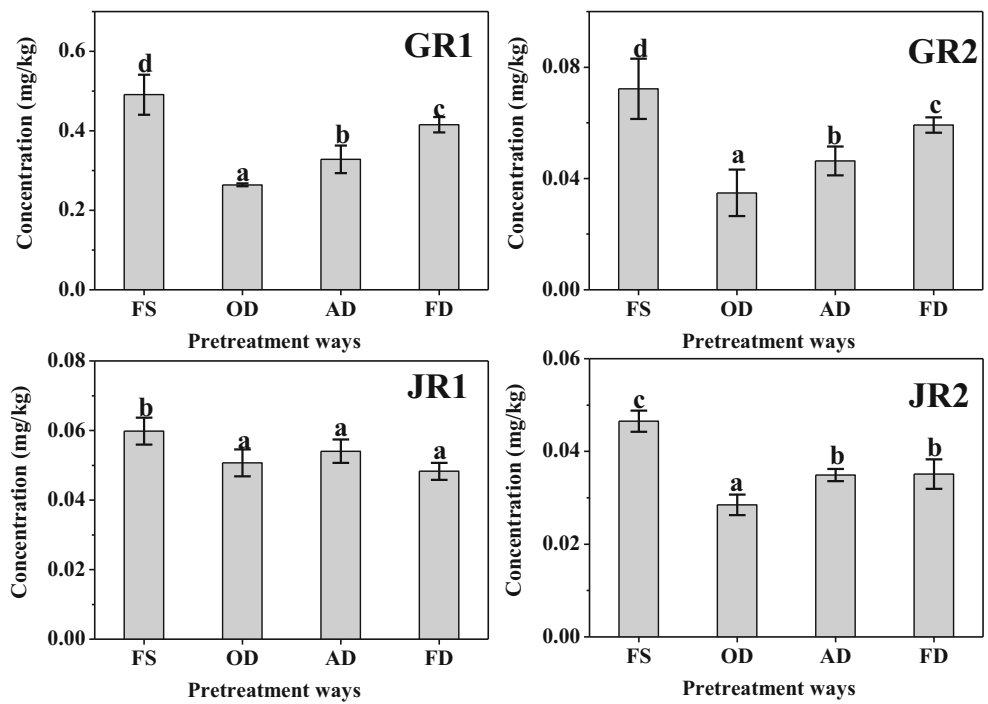

2006). Furthermore, the oxidation of organic matter during the drying process can also facilitate the crystallization of iron oxides (Kodama and Schnitzer 1977; Huang et al. 2015).

\section{Total Hg contents}

As shown in Fig. 6 and Table 4, the total Hg contents in the sample by dried pretreatments exhibited a decrease compared with the FS. In this process, a part of the elemental $\mathrm{Hg}$ would be volatilized. In addition, a part of the organic $\mathrm{Hg}$ (e.g., $\mathrm{MeHg}$ ) could be photodegraded and transformed to elemental Hg (Li et al. 2010; Black et al. 2012), resulting in $\mathrm{Hg}$ loss because of volatilization. The reduction rates of the total $\mathrm{Hg}$ contents in GR1 were higher than those in other samples, and the reduction rates of $\mathrm{OD}, \mathrm{AD}$, and $\mathrm{FD}$ were $-22.50 \%,-15.10 \%$, and $-8.71 \%$, respectively. This was mainly because a much higher proportion of elemental $\mathrm{Hg}(0.491$ vs. 0.072 for GR2, 0.060 for JR1, and 0.047 for JR2, $\mathrm{mg} / \mathrm{kg})$ and the F3 fraction $(0.267$ vs. 0.094 for GR2, 0.159 for JR1, and 0.208 for JR2, $\mathrm{mg} / \mathrm{kg}$ ) were occupied in GR1 compared with other sampling sites. Accordingly, more elemental $\mathrm{Hg}$ may be lost in the drying process.
Fig. 5 Drying influence on the F5 fraction in the different sediment samples
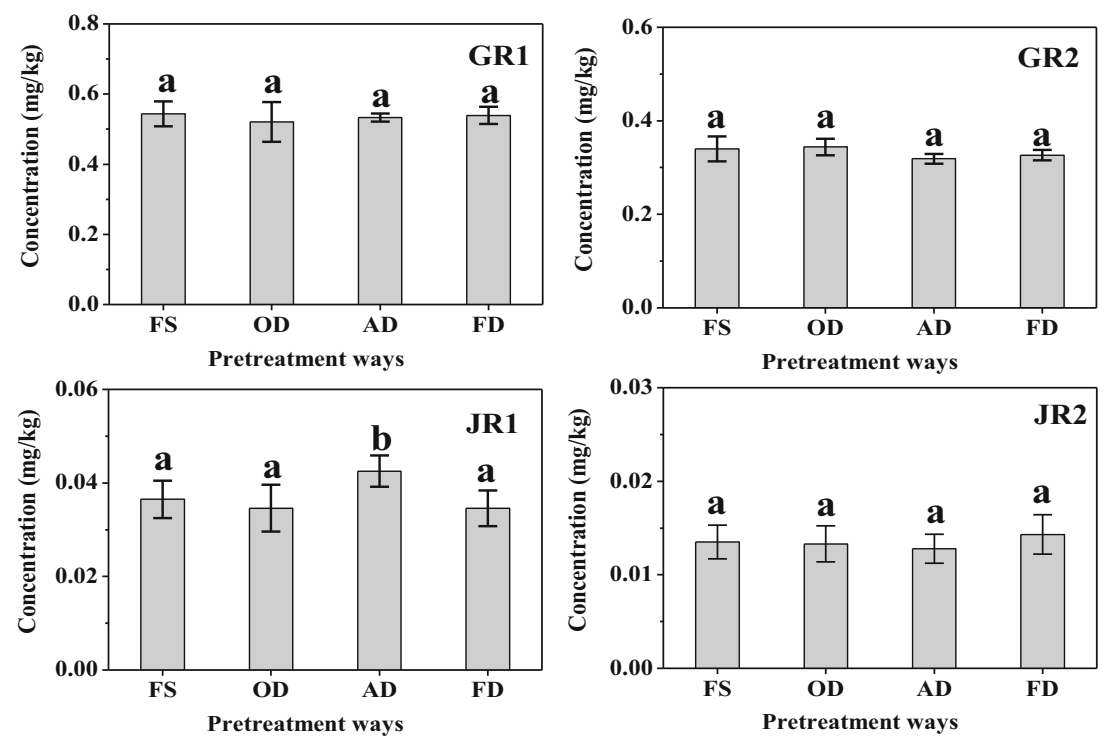


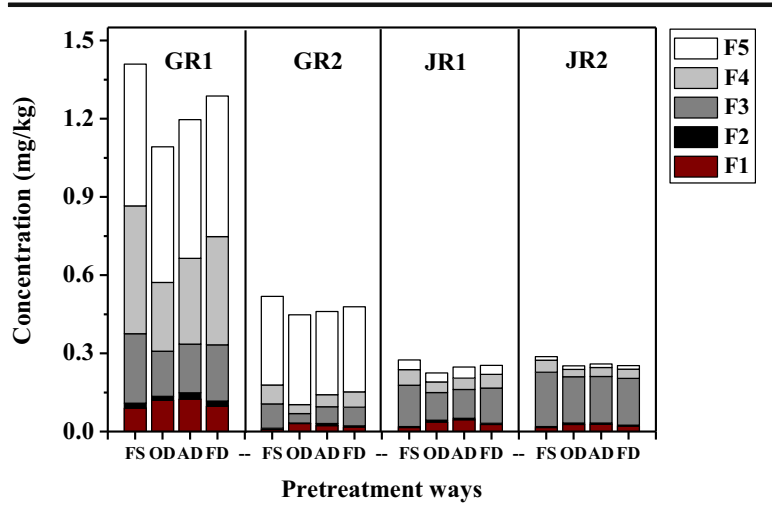

Fig. 6 Drying influences on the total $\mathrm{Hg}$ and the different fractions in sediments

Comparison of the effects of the drying method on the $\mathrm{Hg}$ fraction

As mentioned above, there were many discrepancies in the $\mathrm{Hg}$ fractions in sediments between drying pretreatments and the FS, indicating the occurrence of redistribution and loss among the $\mathrm{Hg}$ fractions. Thus, the most accurate way to analyze the $\mathrm{Hg}$ fraction was to use fresh sediments. Nevertheless, the reproducibility of quantitative analyses with wet (fresh) sediment samples is unsatisfactory compared with dried samples because homogeneous samples are difficult to obtain and the moisture content in different sediments varies greatly; moreover, the acidity of digestion is significantly diluted by water in sediments (Baeyens et al. 2003; Huang et al. 2015). Hence, the preserving of sediment samples is essential given by the inconvenience of field work; the use of drying pretreatments prior to $\mathrm{Hg}$ extraction in sediments is ineluctable.

The Pearson correlation analysis of the $\mathrm{Hg}$ fractions in fresh sediments and drying pretreatment sediments indicates that pretreatment drying methods can minimize negative influences. As shown in Table 5, significant $(P<0.05)$ or extremely significant $(P<0.01)$ correlations between the three pretreatments and the fresh sediment were observed. Remarkably, the Pearson

Table 4 The change rates of different pretreatments for total $\mathrm{Hg}$ compared with FS

\begin{tabular}{lllll}
\hline Pretreatment & GR1 $(\%)$ & GR2 (\%) & JR1 (\%) & JR2 (\%) \\
\hline OD & -22.50 & -13.63 & -18.04 & -12.45 \\
AD & -15.10 & -11.15 & -9.71 & -9.96 \\
FD & -8.71 & -7.58 & -7.53 & -11.94 \\
\hline
\end{tabular}

Table 5 Pearson correlation of $\mathrm{Hg}$ fractions between fresh sediments and drying pretreatments

\begin{tabular}{lllll}
\hline & GR1 & GR2 & JR1 & JR2 \\
\hline OD-FS & $0.904 *$ & $0.973 * *$ & $0.969^{* *}$ & $0.993 * *$ \\
AD-FS & $0.946^{*}$ & $0.992^{* *}$ & $0.945^{*}$ & $0.995 * *$ \\
FD-FS & $0.990^{* *}$ & $0.997 * *$ & $0.995^{* *}$ & $0.998^{* *}$ \\
\hline
\end{tabular}

*Correlation is significant at the 0.05 level

$* *$ Correlation is significant at the 0.05 level

correlation coefficient of FD-FS was higher than that of OD-FS or AD-FS in all sampling sites, and this indicated that the analysis results of FD were more consistent with FS. Therefore, the pretreatment of FD was more suitable to dry sediments in the study, and the ovendrying and air-drying pretreatment methods are not recommended for $\mathrm{Hg}$ fraction analysis in sediments due to the lower correlation coefficients of OD-FS and AD-FS.

\section{Conclusion}

Notable changes of the $\mathrm{Hg}$ fractions in sediments between fresh samples and dried pretreatment samples were observed, implying that transformation existed among different $\mathrm{Hg}$ fractions in sediments during drying pretreatments. Overall, sediments with the exception of FD, air-dried, or oven-dried pretreatments significantly elevated the F1 and F2 fractions compared with fresh sediments, whereas the F3 and F4 fractions were reduced. These results were mainly due to the oxidation and the decomposition of organic matters and sulfides in the aging process accompanying with the $\mathrm{Hg}$ diffusion. Furthermore, the transfer and volatilization of elemental $\mathrm{Hg}$ during the drying pretreatments were the important factor affecting accuracy. Due to slighter oxidation effect, the minor changes were observed at FD samples. Pearson correlation analysis revealed that pretreatments with FD can greatly minimize the deviations compared with $\mathrm{FS}$ in the $\mathrm{Hg}$ fraction analysis. Thus, FD methods on sedimental samples can be selected as the most appropriate drying method for $\mathrm{Hg}$ fraction determination in further study.

Funding information This study was supported by the Strategic Priority Research Program of the Chinese Academy of Sciences (CAS) (Grant No. XDA23050203) and the National Natural Science Foundation of China (Grant No. 41373100). Additional support was provided by the Regional Key Project of STS of 
CAS (Grant No. KFJ-STS-QYZX-057) and the Key Research and Development Program of Shandong Province (Grant No. 2019GSF109002).

\section{References}

Azad, A. M., Frantzen, S., Bank, M. S., Johnsen, I. A., Tessier, E., Amouroux, D., Madsen, L., \& Maage, A. (2019). Spatial distribution of mercury in seawater, sediment, and seafood from the Hardangerfjord ecosystem, Norway. Science of the Total Environment, 667, 622-637.

Baeyens, W., Monteny, F., Leermakers, M., \& Bouillon, S. (2003). Evaluation of sequential extractions on dry and wet sediments. Analytical and Bioanalytical Chemistry, 376(6), 890-901.

Barrow, N. J. (1992). A brief discussion on the effect of temperature on the reaction of inorganic ions with soil. Journal of Soil Science, 43(1), 37-45.

Black, F. J., Poulin, B. A., \& Flegal, A. R. (2012). Factors controlling the abiotic photo-degradation of monomethylmercury in surface waters. Geochimica et Cosmochimica Acta, 84, 492-507.

Bloom, N. S., Preus, E., Katon, J., \& Hiltner, M. (2003). Selective extractions to assess the biogeochemically relevant fractionation of inorganic mercury in sediments and soils. Analytica Chimica Acta, 479(2), 233-248.

Bottrell, S. H., Mortimer, R. J., Davies, I. M., Martyn Harvey, S., \& Krom, M. D. (2009). Sulphur cycling in organic-rich marine sediments from a Scottish fjord. Sedimentology, 56(4), 1159-1173.

Budianta, W., Fahmi, F. L., \& Warmada, I. W. (2019). The distribution and mobility of mercury from artisanal gold mining in river sediments and water, Banyumas, Central Java, Indonesia. Environmental Earth Sciences, 78(3), 90.

Cabon, J. Y., Giamarchi, P., \& Le Floch, S. (2010). A study of marine pollution caused by the release of metals into seawater following acid spills. Marine Pollution Bulletin, 60(7), 9981004.

Claff, S. R., Burton, E. D., Sullivan, L. A., \& Bush, R. T. (2010). Effect of sample pretreatment on the fractionation of $\mathrm{Fe}, \mathrm{Cr}$, $\mathrm{Ni}, \mathrm{Cu}, \mathrm{Mn}$, and $\mathrm{Zn}$ in acid sulfate soil materials. Geoderma, 159(1-2), 156-164.

Di Toro, D. M., Mahony, J. D., Hansen, D. J., Scott, K. J., Carlson, A. R., \& Ankley, G. T. (1992). Acid volatile sulfide predicts the acute toxicity of cadmium and nickel in sediments. Environmental Science \& Technology, 26(1), 96-101.

Fernández-Martínez, R., \& Rucandio, I. (2013). Assessment of a sequential extraction method to evaluate mercury mobility and geochemistry in solid environmental samples. Ecotoxicology and Environmental Safety, 97, 196-203.

Habicht, K. S., \& Canfield, D. E. (1997). Sulfur isotope fractionation during bacterial sulfate reduction in organic-rich sediments. Geochimica et Cosmochimica Acta, 61(24), 53515361.

Haitzer, M., Aiken, G. R., \& Ryan, J. N. (2003). Binding of mercury (II) to aquatic humic substances: influence of $\mathrm{pH}$ and source of humic substances. Environmental Science \& Technology, 37(11), 2436-2441.
Hellmann, C., Costa, R. D., \& Schmitz, O. J. (2019). How to deal with mercury in sediments? A critical review about used methods for the speciation of mercury in sediments. Chromatographia, 82(1), 125-141.

Huang, G., Chen, Z., Sun, J., Liu, F., Wang, J., \& Zhang, Y. (2015). Effect of sample pretreatment on the fractionation of arsenic in anoxic soils. Environmental Science and Pollution Research, 22(11), 8367-8374.

Huerta-Diaz, M. A., Tessier, A., \& Carignan, R. (1998). Geochemistry of trace metals associated with reduced sulfur in freshwater sediments. Applied Geochemistry, 13(2), 213233.

Jiang, G. B., Shi, J. B., \& Feng, X. B. (2006). Mercury pollution in china: an overview of the past and current sources of the toxic metal. Environmental Science \& Technology, 15, 3673-3678.

Kang, S., Huang, J., Wang, F., Zhang, Q., Zhang, Y., Li, C., Wang, L., Chen, P., Sharma, C. M., Li, Q., Sillanpää, M., Hou, J., Xu, B., \& Guo, J. (2016). Atmospheric mercury depositional chronology reconstructed from lake sediments and ice core in the Himalayas and Tibetan Plateau. Environmental Science \& Technology, 50(6), 2859-2869.

Klitzke, S., \& Lang, F. (2007). Hydrophobicity of soil colloids and heavy metal mobilization. Journal of Environmental Quality, 36(4), 1187-1193.

Kodama, H., \& Schnitzer, M. (1977). Effect of fulvic acid on the crystallization of Fe (III) oxides. Geoderma, 19(4), 279-291.

Leopold, K., Foulkes, M., \& Worsfold, P. (2010). Methods for the determination and speciation of mercury in natural waters - a review. Analytica Chimica Acta, 663(2), 127-138.

Li, Y., Mao, Y., Liu, G., Tachiev, G., Roelant, D., Feng, X., \& Cai, Y. (2010). Degradation of methylmercury and its effects on mercury distribution and cycling in the Florida Everglades. Environmental Science \& Technology, 44(17), 6661-6666.

Liu, Q., Wang, F., Meng, F., Jiang, L., Li, G., \& Zhou, R. (2018). Assessment of metal contamination in estuarine surface sediments from Dongying City, China: use of a modified ecological risk index. Marine Pollution Bulletin, 126, 293-303.

Long, Y. Y., Hu, L. F., Wang, J., Fang, C. R., He, R., Hu, H., \& Shen, D. S. (2009). Effect of sample pretreatment on speciation of copper and zinc in MSW. Journal of Hazardous Materials, 168(2-3), 770-776.

Ma, Y., Lombi, E., Nolan, A. L., \& McLaughlin, M. J. (2006). Short-term natural attenuation of copper in soils: effects of time, temperature, and soil characteristics. Environmental Toxicology and Chemistry: An International Journal, 25(3), $652-658$.

Ma, T., Sheng, Y., Meng, Y., \& Sun, J. (2019). Multistage remediation of heavy metal contaminated river sediments in a mining region based on particle size. Chemosphere, 225, $83-92$.

Machado, A. A. S., Spencer, K., Kloas, W., Toffolon, M., \& Zarfl, C. (2016). Metal fate and effects in estuaries: a review and conceptual model for better understanding of toxicity. Science of the Total Environment, 541, 268-281.

Meysman, F. J., \& Middelburg, J. J. (2005). Acid-volatile sulfide (AVS) - a comment. Marine Chemistry, 97(3-4), 206-212.

Morse, J. W., \& Rickard, D. (2004). Peer reviewed: chemical dynamics of sedimentary acid volatile sulfide. Environmental Science \& Technology, 38, 131A-136A.

Nemati, K., Bakar, N. K. A., Abas, M. R., \& Sobhanzadeh, E. (2011). Speciation of heavy metals by modified BCR 
sequential extraction procedure in different depths of sediments from Sungai Buloh, Selangor, Malaysia. Journal of Hazardous Materials, 192(1), 402-410.

Pan, K., \& Wang, W. X. (2012). Trace metal contamination in estuarine and coastal environments in China. Science of the Total Environment, 421, 3-16.

Pignotti, E., Guerra, R., Covelli, S., Fabbri, E., \& Dinelli, E. (2018). Sediment quality assessment in a coastal lagoon (Ravenna, NE Italy) based on SEM-AVS and sequential extraction procedure. Science of the Total Environment, 635, 216-227.

Quazi, S., Sarkar, D., \& Datta, R. (2011). Changes in arsenic fractionation, bioaccessibility and speciation in organoarsenical pesticide amended soils as a function of soil aging. Chemosphere, 84, 1563-1571.

Sheng, Y., Sun, Q., Shi, W., Bottrell, S., \& Mortimer, R. (2015). Geochemistry of reduced inorganic sulfur, reactive iron, and organic carbon in fluvial and marine surface sediment in the Laizhou Bay region, China. Environmental Earth Sciences, 74(2), 1151-1160.

Thompson, A., Chadwick, O. A., Rancourt, D. G., \& Chorover, J. (2006). Iron-oxide crystallinity increases during soil redox oscillations. Geochimica et Cosmochimica Acta, 70(7), 1710-1727.

Zhang, S., Wang, S., \& Shan, X. Q. (2001). Effect of sample pretreatment upon the metal speciation in sediments by a sequential extraction procedure. Chemical Speciation \& Bioavailability, 13(3), 69-74.

Zhong, H., \& Wang, W. X. (2008). Effects of sediment composition on inorganic mercury partitioning, speciation and bioavailability in oxic surficial sediments. Environmental Pollution, 151(1), 222-230.

Zhu, Z., Xue, J., Deng, Y., Chen, L., \& Liu, J. (2016). Trace metal contamination in surface sediments of intertidal zone from Qinhuangdao, China, revealed by geochemical and magnetic approaches: distribution, sources, and health risk assessment. Marine Pollution Bulletin, 105(1), 422-429.

Publisher's note Springer Nature remains neutral with regard to jurisdictional claims in published maps and institutional affiliations. 